\title{
Biography: Karen Flanders, MSN, ARNP, CBN
}

\section{Karen Flanders ${ }^{1}$}

Published online: 14 September 2020

(C) Springer Science+Business Media, LLC, part of Springer Nature 2020

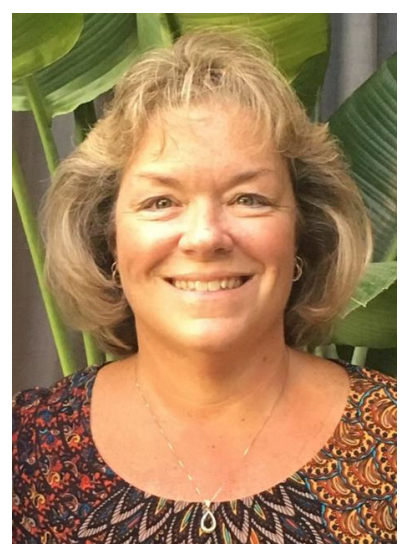

Karen Flanders is a nurse practitioner who began her career in metabolic and bariatric surgery as an advanced practice provider in 2000. Prior to her role as a nurse practitioner, Ms. Flanders' nursing career began after graduating from the University of New Hampshire with her Bachelor of Science degree in nursing in 1985. Her career includes several years working as a staff nurse on a medical surgical unit as well as specializing as a step-down nurse caring for postoperative cardiothoracic patients.

In 1991, Ms. Flanders returned to the University of New Hampshire to advance her nursing degree, and in 1996 graduated with a Master of Science degree in the Family Nurse Practitioner program. She is currently certified through both the American Nurses Credentialing Center and the American Association of Nurse Practitioners as a Family Nurse Practitioner.

Karen Flanders

KMFLANDERS@mgh.harvard.edu

1 Department of Surgery, Massachusetts General Hospital, Boston, MA 02114, USA
After several years of unsuccessfully searching for employment as a nurse practitioner, Ms. Flanders was approached by two general surgeons in 2000, looking to start up a bariatric surgery program and in need of a nurse practitioner. Not knowing what bariatric surgery was and thinking this would be a great "stepping-stone" in her advanced practice career, Ms. Flanders accepted the nurse practitioner/nurse coordinator position. Little did she know, this specialty would become her passion.

Ms. Flanders' experience within the specialty of metabolic and bariatric surgery includes preoperative and postoperative outpatient care, as well as in-patient care. She has worked in both academic- and community-based programs as both a nurse practitioner and coordinator and has also functioned as the clinical reviewer entering data into the MBSAQIP database.

Her enthusiasm for the specialty convinced Ms. Flanders to become actively involved with the American Society for Metabolic and Bariatric Surgery (ASMBS). Her involvement started as the co-leader of the Professional Networking Group for Advanced Practice Providers, and included participating as a moderator, speaker, and program chair at local, national, and international conferences. Ms. Flanders has also received certification as a Certified Bariatric Nurse (CBN) through the ASMBS and has contributed as an item writer for the CBN. She has been actively involved on several Integrated Health committees including Clinical Issues, Professional Education and Program, Corporate Council Steering Committee, and the Integrated Health Executive Council. Ms. Flanders is the current chair of the Advanced Practice Provider Committee and has been working with committee members to develop a certificate program for advanced practice providers. She is also the immediate past Integrated Health President of ASMBS.

In addition to her activities with ASMBS, Ms. Flanders has also been instrumental in contributing to educational materials for the Obesity Action Coalition. She has been the editor of content for Chapter 20 "Nutritional Problems" for both the 10th and 11th editions of the Lippincott Manual of Nursing 
Practice. Her other contributions to science include being a contributing author of the "Clinical Practice Guidelines for the Preoperative Nutrition, Metabolic, and Nonsurgical Support of Patients Undergoing Bariatric Procedures - 2019 Update: Cosponsored by American Associations of Clinical Endocrinologists/American College of Endocrinology, The Obesity Society, American Society for Metabolic and Bariatric Surgery, Obesity Medicine Association, and American Society of Anesthesiologists - Executive Summary", and "Gastric Band Adjustment Credentialing Guidelines for Physician Extenders."

Most recently, Ms. Flanders was recognized through the ASMBS for her contributions and awarded the Integrated
Health Circle of Excellence award as well as the Distinguished Service award in 2019. She stays actively involved within the specialty as an abstract reviewer for the journals Obesity Surgery and Surgery for Obesity and Related Diseases.

Twenty years later, Ms. Flanders continues to work within metabolic and bariatric surgery as a nurse practitioner and coordinator at Massachusetts General Hospital's Weight Center.

Publisher's Note Springer Nature remains neutral with regard to jurisdictional claims in published maps and institutional affiliations. 